\title{
Innovative Developments in Electro-Flocking Technology
}

\author{
Shlyakhtenko Pavel Grigorevich \\ Candidate of Physical and Mathematical Sciences, Doctor of Technical Sciences, Professor Emeritus, \\ St. Petersburg State University of Industrial Technology and Design, Russia
}

Received:December 14, 2018; Accepted: December 27, 2018; Published: January 02, 2019

*Corresponding author: Shlyakhtenko Pavel Grigorevich, Candidate of Physical and MathematicalSciences, Doctor of Technical Sciences, Professor Emeritus, St. Petersburg State University of Industrial Technology and Design, Russia, Email: pavelshl2012@yandex.ru

\section{Annotation}

When studying contact charging and the trajectories of motion of short synthetic charged fibers in a non-uniform electric field, original results were obtained.

Their comprehension led to the creation of a new theory of pile covering, the use of the recommendations of which made it possible to develop a method for obtaining coatings whose surface density of the oriented pile is an order of magnitude higher than the maximum values achievable on the equipment existing to date, as well as developing fundamentally new methods for monitoring the conductivity of the pile, practically identical to the production conditions in which this parameter is used.

Keywords: Electro Flocking; Surface Pile Density; Control of Pile Conductivity under Production Conditions

\section{Introduction}

Historical museums and houses contain a large number of historic carpets. Many researchers have pointed out that the original home of carpet makers is central Asia. This historic carpet is made of textile fibers, most notably wool fibers and silk fibers used in the manufacture of carpets. Different kind of natural dyes $s$ and natural fibers were used manufacturing of the historical carpets. Historical carpets are exposed to many deterioration factors that cause damage and decay in fibers and dyes. Deterioration factors such as oscillate relative humidity $(\mathrm{RH})$, changing temperature, effect of light, effect of air pollution which results in weakness in fibers and dye, hardness in fibers, separate parts, loss parts, stain and dust [1] [2] [3-5].

\section{The Object}

The surface density of the pile coating is the main characteristic of the quality and consumer properties of the pile material. The higher it is, the higher the resistance to abrasion, the durability of the coating and its appearance.

Traditionally, an increase in the density of the pile coating is attempted to be achieved by improving the quality of the preprocessing of the pile, by experimentally selecting the appropriate values of the application process parameters, and also by increasing the duration of the adhesive base in the flocking zone [1,2].

Unfortunately, all these attempts do not lead to a significant increase in the pile density, which is always much less than the calculated theoretical values obtained under the assumption that the fibers are perfectly parallelized in the direction perpendicular to the pile surface of the material (Figure 1-a). (Figure 1)

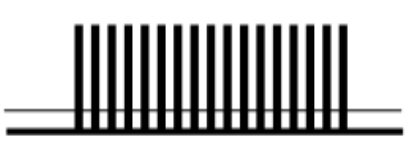

$a$

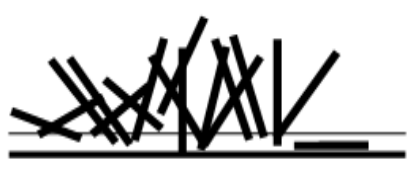

6

Figure 1: Sections of ideal (a) and real (b) electro-flocking coating 
A microscopic study of the surface of the pile material obtained by the electro flocking method shows that the limiting values of the density under discussion are limited by the form of the actual angular random disordered deflection of the fibers that have penetrated the adhesive base relative to the normal to the surface of the coating. In this distribution (Figure 1-b) there are always fibers with large deflection angles, which do not allow the flying fibers to adhere to the adhesive base and thereby increase the coating density [1].

The theory developed in [1-3] connects such a random angular spread in the position of entrenched fibers with oscillation of the fibers relative to the direction of motion during this movement, depending on the excess charge on the fiber and its geometrical parameters.

\section{Purpose of the study}

Develop ways to increase the surface density of the pile in coatings such as artificial fur and suede, obtained by the method of electro-flocking.

\section{Results and discussion}

In [4], the behavior of short synthetic fibers with geometrical parameters $\mathrm{l}=(0,5-3) \mathrm{mm}, \mathrm{d}=(10-30) \mu \mathrm{m}$, moving between horizontal electrodes, with contact charging of the fibers on the electrodes [5]. The successive stages of this process are schematically fixed in Figure 2 (items 1-9).

This Figure shows new, previously unknown stages (sections 4-5 and 8-9), formulated as "the effect of lodging charged when in contact with the pile electrode on the electrode to which they fly up". It is shown that the recharge time of the fibers at each electrode depends on the conductivity of the fibers and the smaller, the higher their conductivity. (Figure 2)

In [6], it was investigated how this effect affects the anchoring of fibers into the glue base. (Figure 3)

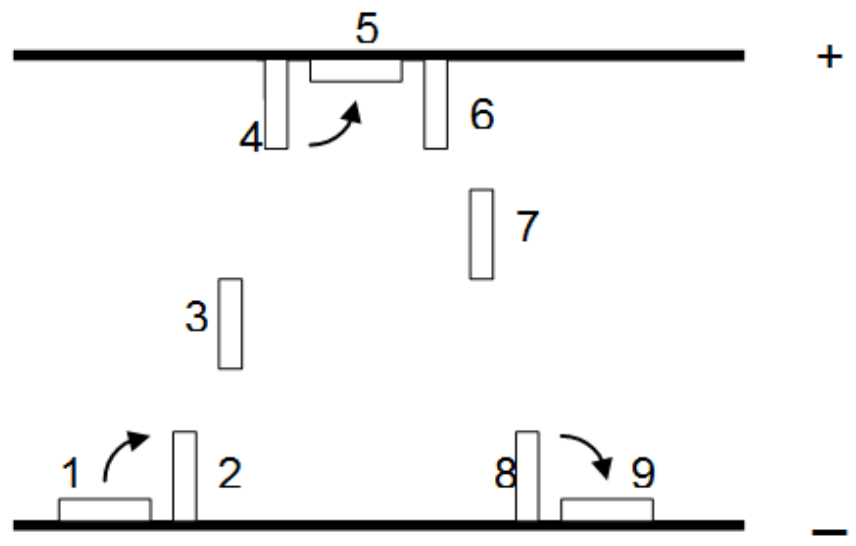

Figure 2: The effect of lodging pile on the electrodes

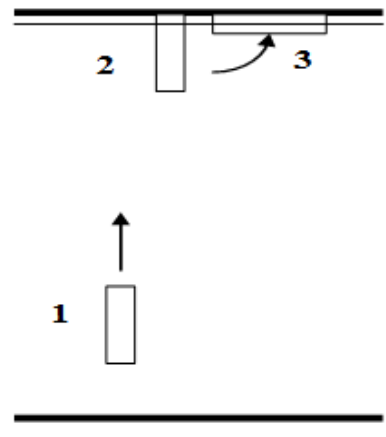

$a$

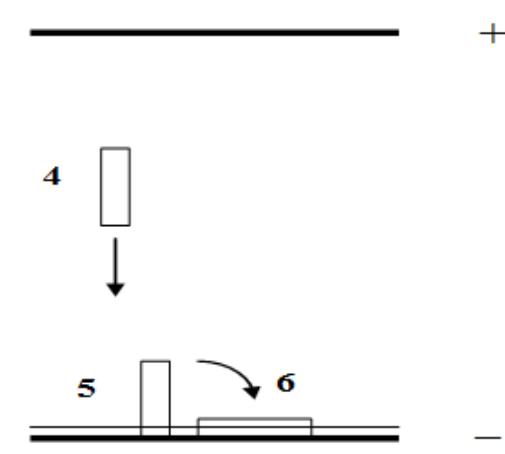

b

Figure 3: Effect of lodging the pile on the glue base: a - on the upper electrode, b - on the lower electrode 
Based on the analysis of the results of this study, the following features of the behavior of fibers were established and explained [7]:

1. All the fibers fly up to the glue base in the direction perpendicular to the glue surface, as in the case of their movement from the bottom upwards (Figure 3-a, p. 1), and from the top downwards (Figure 3-b, p. 4 ).

2. With sufficiently liquid glue and a low feed rate of fibers in the flocking zone, all the fibers will fall into the glue (Figure 3 , pp 2-3 and pp 5-6). The lodging time of the fibers on the electrode depends on the conductivity and viscosity of the adhesive, as well as on the conductivity of the fibers. The lower the viscosity and the greater the conductivity of the pile, the shorter the time.

3. There is a statistical variation in the behavior of the fibers. With greater viscosity and insufficient supply of fibers, some of them go to glue. Others, deviating towards the glue base at a certain angle, remain in this position. Still others, having recharged, straighten up. What exactly happens with each fiber depends on the deviations in the geometry of the fibers and the proximity of the attached adjacent fibers.

4. With a greater supply of fibers, the result is a pile coating consisting of fibers of all types, i.e. exactly that which is obtained with the existing standard electro-floating methods.

Based on the analysis of these patterns in [7], the author proposed a new phenomenological theory of the formation of a pile coating in the method of electro-flocking, which is fundamentally different from the generally accepted concepts [1 $-3,8]$.

The main provisions of this theory are set out and illustrated in [7]:

1. The ideal nap of coatings obtained by this method is the most dense and uniformly fixed pile covering in the adhesive base, in which all the fibers are oriented perpendicular to this base.

2. The experiment shows that when electro-flocking, charged fibers always fly oriented perpendicular to the adhesive base.

3. The existing angular spread of the fixed fibers in the real pile coating obtained by electro-floating is not due to the random angular deviation of the fiber from the vertical at the moment it touches the surface of the glue, as described in the monographs [1 - 3], but by the field effect Gania charged lint into the adhesive base discussed above.

4. The average lodging time of the fibers $\tau p$ depends on the geometry of the fibers, their conductivity, the viscosity of the adhesive and its adhesion to the fiber material.

5. In addition to the effect of lodging, a competing mechanism of recharging the entrenched fibers acts simultaneously with it, when a moment of force acts on the fiber after its charging which returns the fiber to a perpendicular position.
6. The average recharge time of the fibers $\tau z$ depends on the conductivity of the fibers and glue.

7. If the ratio $\tau 3>>\tau \Pi$ (the conductivity of the fibers is low and the glue is liquid) is fulfilled, then most of the fibers sink in the glue, not having time to recharge.

8. If the inverse relationship between these values is $\mathrm{\tau z}<<$ tp (high conductivity, viscous glue), the fibers have time to recharge before they noticeably deviate from the vertical due to the effect of lodging, and will begin to straighten again.

9. At a high concentration of incoming oriented fibers to the glue base, at the initial moment of electro-flocking, the fibers will not be able to deviate by a considerable angle in time $\tau 3$, since this will prevent the neighboring fibers that are simultaneously charged with the same charge mark. After this time, the entrenched fibers straighten and form vacant places to anchor the newly arrived fibers. Therefore, it is legitimate to conclude that the concentration of charged hair-con at the initial moment directly in the flocking zone of the adhesive base determines the final shape of the angular distribution function of the fibers and the surface density of the oriented pile in the finished coating. And the greater the concentration of charged fibers directly at the glue base at the very beginning of electro-flocking, the higher should be the density and orientation of the fibers in the final coating.

10. In the existing methods of electro-flocking to increase the supply of lint to the glue base, the speed of wiping the lint through the bunker mesh is increased, not paying attention to the fact that the charge time of the lint on the net is reduced accordingly and, consequently, the average excess charge is reduced fibers. In addition, on the way to the glue base, the moving fibers are affected by mutual Coulomb repulsion forces, which are proportional to the concentration of charged fibers and the charge on each fiber, which reduce the concentration of the charged pile directly at the glue base. This circumstance makes it impossible to significantly increase the concentration of the charged pile at the glue base.

11. It was experimentally shown that during contact charging of the pile on the lower electrode, the fibers receive a much larger (by orders of magnitude) and more uniform excess charge than when charged by other methods, which should positively affect.

In [8], to increase the concentration of cotton fibers on the vertical axis of symmetry, a non-uniform electrostatic field was used, formed by a system of horizontal electrodes, similar to those shown in Figure 4-a. Such a design of electrodes was working in a system of non-curled electrostatic straining developed by the authors [8]. The electric field strength generated by such electrodes, in any horizontal section, is maximum at points on the vertical axis of symmetry of the electrodes. (Figure 4) 

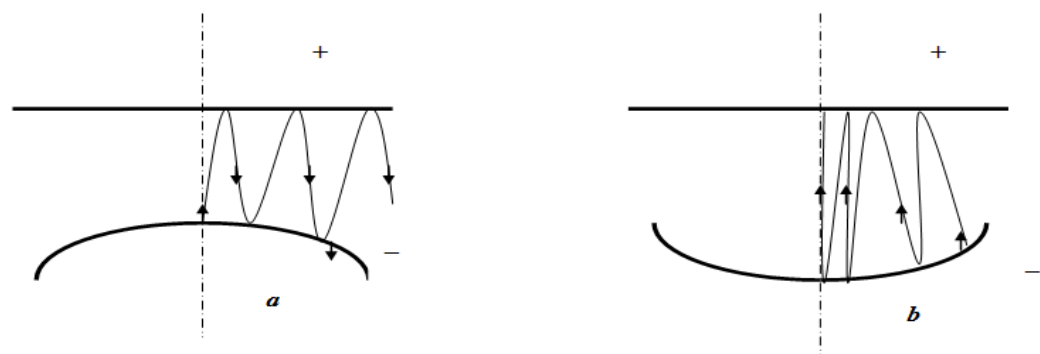

Figure 4: Movement of a short fiber when it is recharged in a system with curved (a) and concave (b) electrodes

According to the theoretical views of the authors of this work, any dielectric fibers rechargeable by contact on the electrodes must, in such a field, under the influence of the ponderomotive forces of the electric field, be drawn into the region of a strong electric field, i.e. move towards this axis.

However, experiments [9] carried out with short synthetic fibers produced the opposite effect. The fibers in this system of electrodes (Figure 4-a) placed before switching on the voltage in the center of the lower electrode, moved in the opposite direction, shown by the arrows in Figure 4-a, after its inclusion.

The system of electrodes that pull such fibers to the axis of symmetry of the electrodes when they are recharged and moving between the electrodes is possessed by the system schematically shown in Figure 4-b, where the arrows indicate the experimentally observed direction of this movement.

It is obvious that such an electrode design increases the concentration of the pile at the upper electrode.

An explanation of the observed effect was given in [10], and a method for applying pile coatings of the type of artificial fur and suede was proposed in [11] using the system of electrodes indicated in Figure 4-b.

In Figure 5 shows comparative micrographs of pile coatings of the type of artificial suede, applied to existing (Figure 5-a) and proposed [10] methods (Figure 5-b) of electro-flocking $n$ for one type of standard nylon pile with geometrical parameters $\mathrm{l}=0,5$ $\mathrm{mm}, \mathrm{d}=15 \mu \mathrm{m}$. (Figure 5)

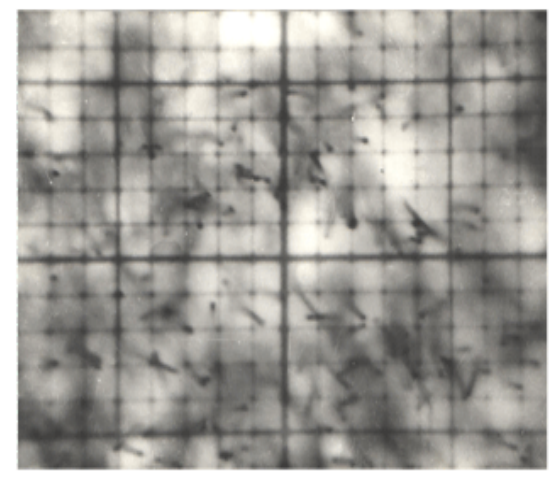

$a$

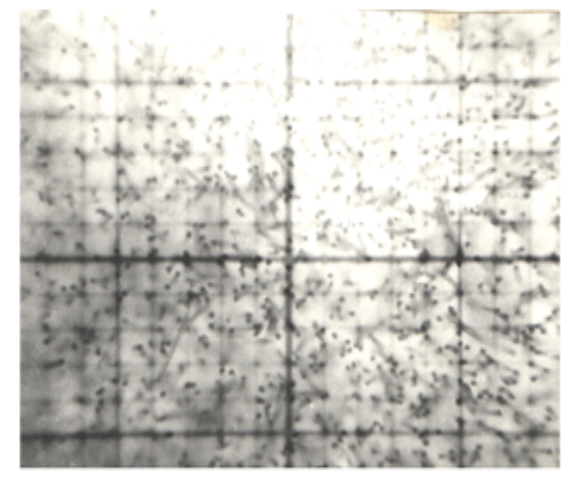

$b$

Figure 5: Comparative micrographs of pile coatings obtained for one type of pile using the existing electro-floating method (a) - $\mathrm{n}=90$ [1 $/ \mathrm{mm} 2]$ and the proposed method (b) - $\mathrm{n}=1000\left[1 / \mathrm{mm}^{2}\right]$

From the data in Figure 5 it follows that in addition to a significant increase in the density of the pile (n) in Figure 5-b compared to Figure 5a, the best orientation of the pile is seen in the direction perpendicular to the adhesive backing. This coating reflects well the incident light according to the laws of reflection from predominantly oriented hair-con ends.

In Figure 6 shows the main parts of a fundamentally new electro-flocker [12] proposed for the continuous deposition of high density roll coatings.
This device implements the recommendations of the new theory of the formation of a pile coating, namely: the creation of a high concentration of charged pile directly in the flocking zone at the initial moment of applying the pile coating; applying the nap according to the bottom-up method and contact charging the nap on the lower electrode. (Figure 6) 


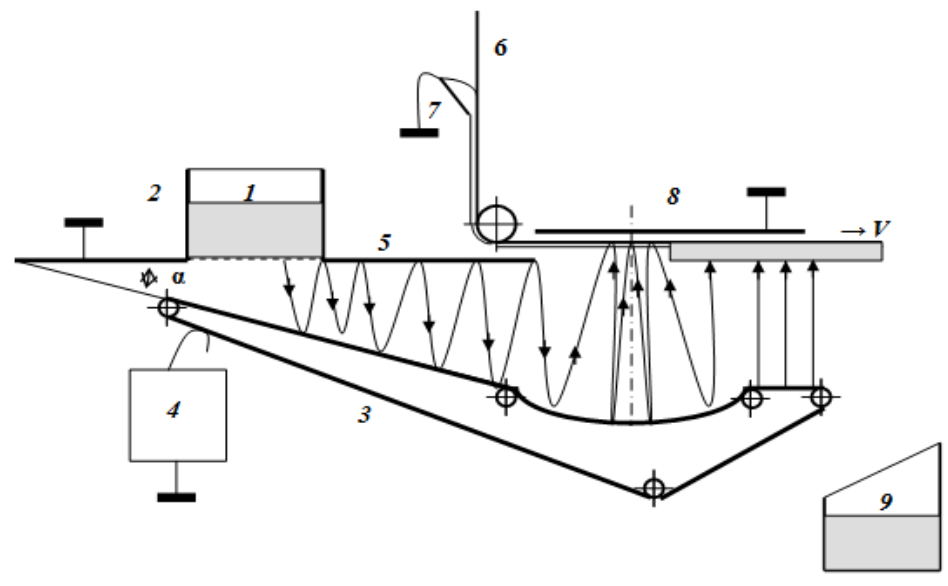

Figure 6: Block diagram of the installation

The latter significantly increases the excess charge on the fibers with more uniform charging, which leads to deeper penetration of the fibers into the glue base.

Pile 1 of the hopper 2 through the mesh bottom wakes up on a moving belt of the trans porter 3 , which is fed with high voltage from the rectifier 4 . The diaphragm 5 closes the space from the bunker to the point of penetration of the fibers charged in the curvilinear section of the conveyor 3 . The flat section of the conveyor is turned relative to the bottom of the bunker at an angle $\alpha$. Fibers, being recharged in the first section of the conveyor belt and diaphragm 5, move, deviating in the direction of weakening the electric field, towards the second section of the tape bent in the form of a section of a cylindrical surface of radius $\mathrm{R}$.

Recharged in this area, they fly towards the adhesive base 6 , formed by a doctor blade 7 , which is grounded, where an increased concentration of fibers is created, which form an initial layer of increased concentration on the adhesive base.
There are no lumps of lint on the conveyor, as they are "resolved" when moving between the conveyor belt in the first section and the diaphragm 5 . The base moves to the right. Therefore, on the adhesive base 6 , an initial layer of increased pile concentration is continuously formed, which then on the third horizontal section of the working surface of the tape grows due to fibers charged on this section of the tape, moving normally to the base, filling the vacant places.

The excess loose fibers collected in the box 9 . The base 6 moves along the upper electrode 8 (horizontal, grounded, removing the charge from the base).

In Figure 7 shows a detailed diagram of some not shown in Figure 6 parts of the above installation, which carry out lateral focusing of the moving pile, concentrating it in the region between the lower and upper electrodes and eliminating its spread in the transverse direction. (Figure 7)

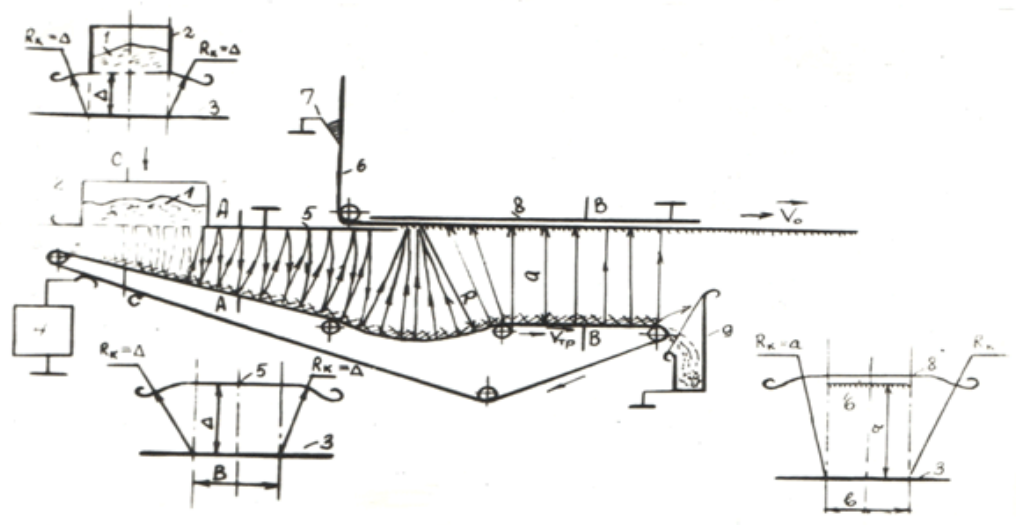

Figure 7: Detailed installation block diagram 
This focusing is provided by the introduction of the edge edges shown in cross sections in Figure 7, which provide a nonuniform electric field of the required configuration on the path of the pile.

In $[13,7]$, a new method for controlling the quality parameters of homogeneous particles (in particular, synthetic pile) used in the application of coatings in an electric field was proposed and substantiated.

In Figure 8 shows the scheme and appearance of the device according to this method, in which the previously mentioned effects of "lodging" [4] and "deviations" [7] are used. (Figure 8)
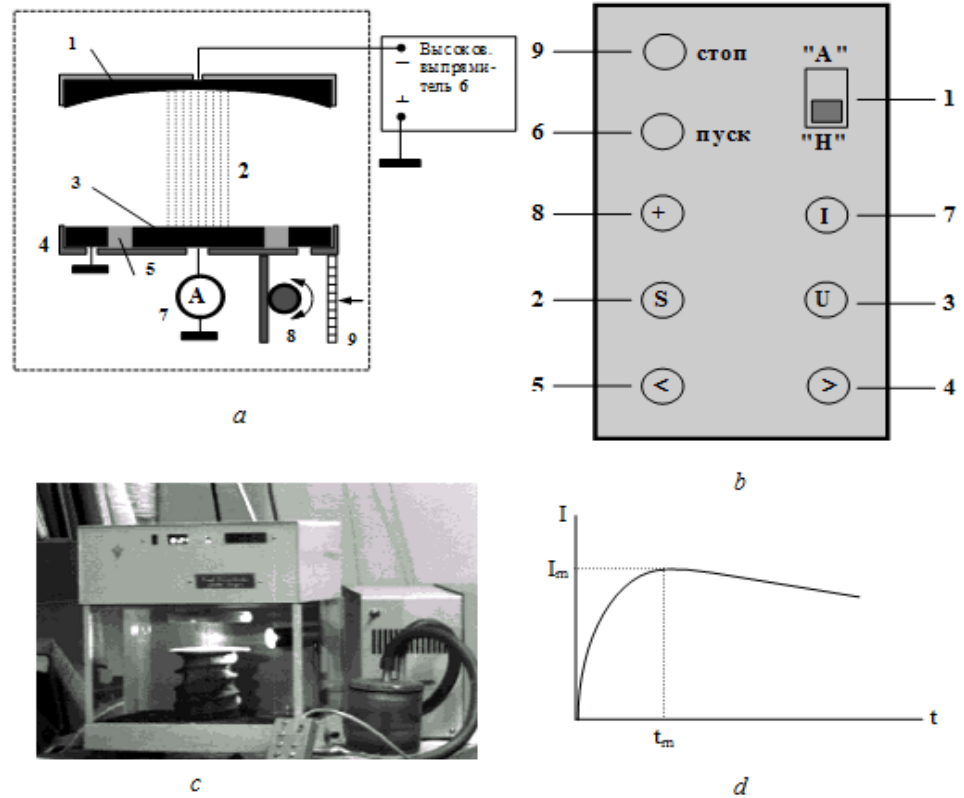

Figure 8: Scheme (a), control panel (b), appearance of the device (c), current I dependence due to particles under study moving between electrodes from time $t$ and fixing time tm of measured current $\operatorname{Im}(d)$

How can you see from the data in Figure 8a, in order to keep a predetermined volume or mass amount of the particles 2 under study moving between horizontal electrodes, near the vertical axis of symmetry, the upper electrode 1 is concave.

The lower electrode is divided into two parts, the internal measuring 3 and the external grounded "guard" ring electrode 4, between which there is a dielectric strip 5.

The current I, due to the charge transfer moving between the measuring 3 and the upper 1 electrodes of the investigated particles 2, is measured by the electronic circuit 7. Its value is displayed on the digital display of the device (Figure 8c).

With the help of the engine and the worm gear 8 , the lower electrode can rise, fall and be set to any desired distance between the electrodes, which is controlled by the digital display of the device (Figure 8c). On the electrode 1 from the stabilized rectifier 6 can be applied to any desired voltage across $1 \mathrm{kV}$ in the range of $1-10 \mathrm{kV}$, which can also be displayed on the digital board of the device.

When high voltage is applied from the control unit (Figure 8-b), the particles (nap), previously poured on the electrode 3 , are charged and set in motion between the electrodes. This leads to an increase in current (Figure 8-d), until all of them are distributed by a uniform layer of the region near the vertical axis of symmetry of the electrodes. After that, the current begins to decrease due to the collision of particles moving in opposite directions. The maximum value of the current Im and the corresponding time tm is recorded in the device's memory, and can be displayed on the device's digital display.

Controlled current value (Im), directly related to the conductivity of the studied particles, and its establishment time (tm), depending on the so-called. "Separability" of particles, is characteristics of their quality, which are recorded in the memory of the device.

Obvious advantages of this device in comparison with its counterparts, used in our country and abroad, are:

1. Controlled parameters are measured under conditions (the amount of electric fields, humidity, temperature, pressure) of almost identical conditions electro-flocking.

2. The device will allow you to work out some flocking modes without switching electro flocking. In particular, the value voltage at which between the electrodes for some types of treated lint is observed the formation of so-called. "Pillars" of the investigated particles, which in the production gives the main defect when they occur. 


\section{Conclusion}

1. Based on the analysis of correct experimental data obtained in the study of contact recharge of the pile on the flock electrodes, a new theory of the formation of a pile coating was proposed. In accordance with this theory, the initial concentration of fibers reaching the glue determines the total surface density of the oriented nap covering.

2. Found the design of the electrodes, creating a non-uniform electric field, focusing the charged when in contact with the electrode fiber directly at the adhesive surface.

3. Taking into account the recommendations of the new theory, a method and appropriate devices are proposed for applying pile coatings in a non-uniform electric field after a record density unattainable by existing methods,

4. A fundamentally new method is proposed for monitoring the conductivity of the pile under conditions that are practically identical to the conditions of electro-flocking.

\section{References}

1. Bershev EN. Fizihesrie osnovi tehnologii elektroflokirovaniya: Izd. LGU. 1984. $232 \mathrm{~s}$.

2. Ivanov OM. Teoretihesrie asperni tehnologii elektroflokirovaniya: SPb. SPGUTD, 2004, $165 \mathrm{~s}$.

3. Semenov VA. Teoriya i praktika elektroflokirovaniya: M. VZPI, 1992, $-152 \mathrm{~s}$
4. Shlyakhtenko PG. Isledovanie povedeniya sintetiheskogo vorsa pri kontaktnoi zaryadke ego na ploskom electrode elektroflokatora // Izv. vuzov. TTP. - 1978. № 5. S. 27-31.

5. Shlyakhtenko PG. O kontaktnoi zaryadke vorsa na elektrodah elektroflokatora // Izv. vuzov. Tehn. Tekst. prom. 1987, № 1, S. 42-47.

6. Shlyakhtenko PG. Isledovanie kinetiki zakrepleniya orientirovannogo sintetiheskogo vorsa $\mathrm{v}$ pole elektroflokatora // Elektronnaya obrabotka materialov. — Kishenev. 1979. —№ 3. - S. 45-48.

7. Pavel Shlyakhtenko. Poleti vorsa vo sne I nayavu. Problemi elektroflokirovaniya: LAP LAMBERT Academic Publishing GmbH \& Co.KG. -2016. -192 s.

8. Popkov V I, Glazov MI. Kinetika zariadki i dinamika volokon v elektriheskom pole. M: Izd. «Nauka», 1976. — $123 \mathrm{~s}$.

9. Shlyakhtenko PG, EN Bershev, EI Firsov. O dvigenii zaryagennih volokon $\mathrm{v}$ neodnorod-nom elektricheskom pole // Elektronnaya obrabotka materialov. - 1984. - № 6. - S. 54-55.

10. Shlyakhtenko PG, Mescheryakova GP. Dvigenie zaryagennih volokon v neodnorodnom elektricheskom pole // Elektrichestvo. - 1991. - № 2. - S. $54-58$.

11. A.s. СССР № 1024538, МКИЗ 04Н 11/00 Sposob polucheniya vorsovogo materiala / P.G. Shlyakhtenko, EN Bershev, EI Firsov. Opubl. 23.06.83. Bul.№23.

12. Patent RF № 2057218. MKI D 04 H 11/00. Ustroistvo dlia electrostaticheskogo naneseniya vorsovih pokritii / PG Shlyakhtenko, IV Kotelnikov. Opubl. 27.03.96. Bul. № 32.

13. Patent RF № 2096790. МKI 5 G 01 R 27/00. Sposob kontrolia parametrov kachestva od-norodnih chastitc ispolzuemih pri nanesenii pokritii v elektrichyheskom pole / PG Shlyakhtenko, A.V. Sergeev. Opubl. 20.11.97. Bul. 32 . 